\title{
ANÁLISIS DEL CULTIVO DE ALCACHOFA EN LA ZONA ANDINA DEL PERÚ
}

\section{ANALYSIS OF ARTICHOKE CULTIVATION IN THE ANDEAN AREA OF PERÚ}

(D) Juan Quispe Rodríguez ${ }^{*}$, (D) José Antonio Quispe Medrano²

jquisper@unah.edu.pe; jhoseph@gmail.com

${ }^{1}$ Universidad Nacional Autónoma de Huanta, Ayacucho, Perú

${ }^{2}$ Consultor de la empresa CANVIA, Lima, Perú

*Correspondencia: Juan Quispe Rodríguez. Email: jquisper@unah.edu.pe

Recibido: 20.11.19 | Aprobado: 03.12.19

\section{RESUMEN}

La alcachofa (Cynara scolymus L.) es un producto de exportación con muchas expectativas en nuestro País, básicamente en la Costa, también en la sierra tiene gran posibilidad, en los valles interandinos en altitudes que van desde los $2500 \mathrm{msnm}$ hasta los $3450 \mathrm{msnm}$ (franja agroclimática que aparentemente le da una mayor calidad comparativa al producto) para el desarrollo de este cultivo, el Ministerio de Agricultura y algunas instituciones privadas vienen promoviendo su cultivo con buenos resultados sobre todo en el valle del Mantaro, luego se masifico a otras zonas del país (Cajamarca, Trujillo, Cusco, Puno, Arequipa, entre otras zonas) las variedades son: criolla (con espinas), green globe y Lorca (sin espinas), comercializados por los productores directamente a las empresas procesadoras dedicadas a la exportación como Danper, Procesadora SAC, Viru, Agro Mantaro, Talsa, etc., cuyo auge se dio en los años de 2010 a 2015. Cabe resaltar la intervención de instituciones financieras que apoyaron proyectos productivos en las zonas mencionadas como la USAID y el FIP, favoreciendo sobre todo a los pequeños productores de la zona andina del Perú.

Palabras clave: Alcachofa, zona andina, variedad, valles interandinos.

\section{ABSTRACT}

The artichoke (Cynara scolymus L.) is an export product with high expectations in our country, basically in the Coast, also in the mountains it has great possibility, in the inter-Andean valleys at altitudes that range from $2500 \mathrm{msnm}$ to $3450 \mathrm{msnm}$ (agroclimatic strip apparent that gives a higher comparative quality to the product) for the development of this crop, the Ministry of Agriculture and some private institutions have been promoting its cultivation with good results, especially in the Mantaro Valley, then it became widespread in other areas of the country ( Cajamarca, Trujillo, Cuzco, Puno, Arequipa among other areas) The varieties are: Creole (with thorns), green globe and Lorca (without thorns), marketed by producers directly to exporting processing companies such as Danper, SAC Processor, Viru, Agro Mantaro, Talsa, etc., whose boom was in the years from 2010 to 2015, the intervention of financial institutions that support yaron productive projects in the mentioned areas such as USAID and the FIP, favoring mainly small producers in the Andean zone of Peru.

Keywords: Artichoke, Andean zone, variety, inter-Andean valleys. 


\section{INTRODUCCIÓN}

La alcachofa (Cynara scolymus) en nuestro país es un producto de cualidades nutricionales y medicinales muy importantes, que a partir del año 1997 se promociono su cultivo con las variedades sin espinas como la green globe, imperial star, Lorca, etc. y la de espinas como la "criolla" principalmente para el mercado de exportación, inicialmente con intervención del Ministerio de Agricultura, SENASA, INIA, (DRA Junín, 1998) y luego con la intervención de entidades privadas como IDEA, Caritas, CESEM, etc., lo cual es una oportunidad para nuestras zonas interandinas de nuestro país constituyéndose en una alternativa viable, los valles interandinos ofrecen las mejores condiciones agroecológicas requeridas para el desarrollo de este cultivo (Quispe R., 2006)

Para ser competitivos en el mercado no solo se requiere tener una oferta exportadora que satisfaga la demanda, además se necesita que los agentes que intervienen dentro de la cadena productiva participen de una manera integrada y eficiente a fin de generar productos con valor agregado (Bezzubikoff, P.Y. et al., 2005)

Una de las debilidades para el éxito de este cultivo, es que los productores de la zona de sierra reciben poco apoyo del Estado en la asesoría y capacitación de los pequeños productores, la poca atención ha hecho que no se avance en esta parte del país con oportunidades de un desarrollo económico social, sumándose a ello la poca o escasa organización y la poca responsabilidad en el cumplimiento de contratos y la insuficiente tecnología para el manejo eficiente de este cultivo para la obtención de altos rendimientos, lo que imposibilita aprovechar con éxito en el mercado nacional e internacional como los tratados comerciales (TLC.)

Es necesario sumar esfuerzos de parte del Estado y la intervención de entidades privadas que promueven cultivos para la exportación, brindando el asesoramiento y capacitación en las zonas donde están ubicados estos pisos ecológicos, con el objetivo de orientar, fomentar y promover el cultivo de la alcachofa con el fin de que los agricultores de cultivos tradicionales opten por un cultivo alternativo que les genere mayores ingresos y con un mercado seguro en el ámbito tanto nacional como el internacional

De acuerdo a Vavilov, la alcachofa es un producto de un amplio número de especies cultivadas que tienen como centro de origen el Mediterráneo. Boswell reporta que fue llevada hacia Egipto y el Lejano oriente hace 2000 a 2500 años. Es posible que las formas consumidas por los romanos y griegos haya sido el cardo comestible, muy parecido a la alcachofa. También es posible que el cardo haya sido utilizado en un inicio de su estado silvestre y más tarde de una planta cultivada. La porción consumida fue probablemente los tallos tiernos, dado que el cardo fue confundido con el espárrago por los primeros investigadores. Los brotes o yemas del cardo son todos pequeños y espinosos y es probable que no hayan sido consumidos. Actualmente se le considera un alimento de lujo, de buena reputación y de precios en ascenso.

La investigación realizada para la sostenibilidad de la industria, concluye en desarrollar capacidades agrícolas en la población del lugar, cambiando calendarios y adaptándolas a la realidad agrícola del lugar, creando posibilidades de fuentes de trabajo en la población local, de esta manera no solo se desarrolla la competitividad de la cadena productiva de la alcachofa en la región Junín, sino que puede ser un referente para otras cadenas productivas en diferentes regiones del país y 
de distintos productos, así mismo acota que para garantizar el éxito de la cadena productiva, es necesario contar con infraestructuras adecuadas, impulsada por el gobierno y complementada por el sector privado que mejoren el transporte, tecnología de riego y el procesamiento (BizzuBikoff et. al., 2005)

\section{DIFUSIÓN DE LA ALCACHOFA}

La alcachofa apenas fue considerada durante el Medioevo, reapareciendo en el siglo XV alrededor de Nápoles, al norte de Venecia y Florencia. Actualmente es descrita en términos modernos. Sin duda fue cultivada para la obtención de las cabezuelas comestibles tal como lo es actualmente. Este cambio pudo haberse dado durante el Medioevo, quizá en las selecciones que se realizaban en los jardines de los Monasterios.

Más tarde fue adoptada por Francia y llegó a Inglaterra en 1548 donde se hizo popular. En los Estados Unidos fue mencionada por primera vez en 1806 en los "Catálogos del Jardinero" de Macmahow, sus semillas se ofrecieron por primera vez en los inicios del siglo XIX, los que fueron de dos tipos: El tipo francés cónico y espinoso, y el tipo globular. Los cultivos modernos varían considerablemente en la forma, tamaño, cantidad de espinas y en el color de las cabezuelas.

En Sudamérica, figuran como principales productores Argentina y Chile y en los últimos años el Perú, que ha pasado a ser uno de los principales productores a nivel mundial. Sobre la introducción de la alcachofa en el Perú, se tienen dos versiones, la primera que fue introducida por los Misioneros Franciscanos de origen europeo del Convento de Ocopa (Concepción - Junín) y se adaptó en la micro cuenca del río Achamayo en la provincia de Concepción (Valle del Mantaro). La otra versión indica que fue introducida por inmigrantes italianos y españoles, asentados en la sierra central del Perú; que por la buena calidad de agua, suelos y microclima especial se adaptó en la micro cuenca del Río Achamayo.

Se recomienda promover la sustitución de cultivos tradicionales de baja rentabilidad por cultivos como la alcachofa en las regiones del Perú, a través de la difusión y capacitación de los órganos de apoyo técnico del Estado, los cuales tendrán la responsabilidad de exponer los beneficios económicos, nutricionales y medicinal de este cultivo.

\section{LA EXPORTACIÓN DE LA ALCACHOFA}

Hacia el año 2004 se inició con el incremento notorio de las exportaciones de hortalizas en el Perú, especialmente de la alcachofa que al igual que el esparrago, se vislumbra como uno de los productos de mayor dinamismo en el mercado de exportación (Aduanas, 2004)

Se dice que el Perú a pesar de tener 128.5 millones de hectáreas, solo 17.5 millones de hectáreas se encuentran bajo riego y son aptas para cultivos agrícolas transitorios, existiendo un potencial de crecimiento importante de por lo menos 3.8 millones de hectáreas que actualmente se encuentran en secano.

Debido a que en los países consumidores de Europa demandan de alcachofas frescas en grandes cantidades con relación a su oferta estacional, les queda poco volumen para la producción de conservas destinadas a cubrir la demanda de la época en que no hay 
cosecha local, lo que nos abre otro mercado que pudiera ser tanto o más grande que el de las alcachofas frescas, especialmente cuando es difícilllegar bien con ellas a los centros de consumo por limitaciones o costo de transporte.

Dado que en nuestro medio es posible obtener cosechas durante amplios períodos del año, pero solo exportar alcachofas frescas durante pocos meses, el mayor volumen de la producción tendrá que ser procesado en conservas y congelado y es aquel mercado donde estará centrado el mayor volumen de nuestras exportaciones, existen solicitudes de España, Italia, Francia y otros países consumidores. Exportaciones relativamente pequeñas de corazones y fondos de alcachofas en salmuera y congelados que van en aumento, teniendo buena acogida en España, que además de consumidora es reexportadora. Italia es también gran importadora de conservas, conociéndose que se abastece comprando un alto porcentaje de la producción española y egipcia, cosa que también hace Francia. Estados Unidos es otro importador, siendo España su principal abastecedora. En todos los casos la mayor demanda es siempre para las conservas en salmuera, debido a que pueden prepararse en distintas formas para su consumo. Por el momento hay varias empresas procesadoras que están instalando plantaciones propias o bajo contrato en diversos puntos del país, destinadas a la exportación de corazones en conserva y congelados.

De otro lado son diferentes los calibres en que se cosechan los capítulos, así como el precio que se paga por ellos; lo que obliga a un manejo diferente de los cultivos para equiparar los resultados económicos, que comienza por la densidad de las plantaciones. También la planta de alcachofa ofrece bondades medicinales que ayudan a prevenir y curar problemas fisiológicos en nuestro organismo, en la actualidad hay productos procesados derivados ya sea en capsulas, jarabes y harinas (Quispe, 2006)

El rendimiento promedio mundial de la alcachofa sin espinas es de 19.4 TM/ha. y los mayores productores son: Italia, España, Argentina, Francia Estados Unidos, Chile y Perú con rendimientos de hasta los 12.9 TM/ha. (Minag, 2004)

Los países importadores de alcachofa son: Canadá, Suiza y Estados Unidos, de todos ellos como objetivo principal para las alcachofas frescas es Estados Unidos, considerando su cercanía geográfica al Perú lo que permite obtener menores costos de transporte. Del mismo modo Estados Unidos es el principal comprador de alcachofas en conservas, registrando importaciones desde el año 2001 en forma sostenida con participación importante a través de los años (Robles, 2002)

Con respecto a los estándares comerciales, la comunidad europea ha sido considerada como referencia para establecer los principales estándares más comunes para la calidad de alcachofas frescas debido a que presenta la mayor experiencia en comercialización de este producto, por tanto, los aspectos más relevantes que se pueden mencionar son los siguientes:

1. Requerimientos mínimos que deben cumplir, especialmente en su aspecto fresco

2. Se establecen categorías de calidad extra, clase I o clase II, diferenciados entre sí por el grado de apertura de las brácteas que conforman la alcachofa y su apariencia. 
3. Clasificación por calibres, medida de diámetro mínimo es de $6 \mathrm{~cm}$. En rangos de $1.5 \mathrm{~cm}$. Hasta alcanzar medidas mayores a $13 \mathrm{~cm}$.

4. Tolerancia de calidad definidas en porcentajes de alcachofa que no satisfacen determinada clase, también se definen tolerancias para el calibre que están en el orden del $10 \%$ de alcachofas son calibres que corresponden al calibre inmediato inferior.

5. Disposiciones sobre la presentación: uniformidad y envasado, lo cual define la forma en que deben presentarse y protegerse las alcachofas.

6. Disposiciones relativas al mercado a fin de identificarlos considerando el nombre del exportador, tipo de producto, origen, especificación comercial

\section{COMPOSICIÓN Y VALOR NUTRITIVO}

La alcachofa contiene bajas calorías y gran cantidad de fibra, estas características hacen que se le considere una hortaliza light. Por otro lado, el consumo de alcachofa ayuda a prevenir problemas circulatorios y cardiovasculares, rica en calcio y vitamina $\mathrm{A}$, así como otros elementos presentados en la tabla 1.

\section{Tabla 1}

Composición quimica y valor nutricional, contenido en $100 \mathrm{gr}$. de alcachofa

\begin{tabular}{lcc}
\hline \multicolumn{1}{c}{ Elemento } & Unid. & Valor \\
\hline Calorías totales & Cal. & 40 \\
Calorías de grasa & Cal. & 0 \\
Agua & gr. & 0.86 \\
Ceniza & gr. & 1.8 \\
Carbohidratos & gr. & 6 \\
Azucares & gr. & 1 \\
Proteínas & gr. & 3.2 \\
Grasas & gr. & 0.2 \\
Fibra & gr. & 3.4 \\
Colesterol & gr. & 0 \\
Calcio & Mgr. & 42 \\
Magnesio & Mgr. & 60 \\
Fosforo & Mgr. & 51.1 \\
Potasio & Mgr. & 310 \\
Hierro & Mgr. & 1.1 \\
Ac. Ascórbico (Vit. C) & Mgr. & 60 \\
Tiamina (Vit. B1) & Mgr. & 0.07 \\
Rivoflavina (Vit. B2) & Mgr. & 0.04 \\
Niacina & Mgr. & 0.85 \\
Retinol (Vit. A) & Mgr. & 50 \\
\hline
\end{tabular}

Fuente: Fausto, R., (2000)

\section{VARIEDADES DE ALCACHOFA}

Las variedades que tradicionalmente se conocen son las de su lugar de origen; como la Blanca de Tudela, Violeta de Provenza, Camus de Bretagne, Romanesco, Lorca, Green globe, Imperial star, entre otros. 
Variedades cultivadas en el Perú

\section{Lorca}

La propagación por semilla botánica y semilla vegetativa, es de crecimiento uniforme en altura y anchura de planta, ahijamiento tardíologrando de 2 a 4 brotes por planta capítulos de forma variable por efectos de temperatura, brácteas jaspeadas con una coloración violeta, verde brillante con hendidura en el ápice

\section{Blanca de Tudela}

Obtenida y propagada vegetativamente a través de esquejes e hijuelos, de porte mediano a bajo, posee gran capacidad de retonar y echar hijuelos. Esta variedad es muy precoz de capítulos de color verde claro compacto y bien formado.

\section{A - 106}

Esta variedad fue propagada por semilla botánica mayormente y de buen vigor, crecimiento uniforme, ahijamiento tardío, sus capítulos son redondas globosas con brácteas jaspeados de color morado en el último tercio y con hendidura en elápice

\section{Green globe}

Sus capítulos son de color verde plateado, y son terminales tanto en el tallo principal como en tallos laterales, pueden llegar a crecer hasta una altura de $2 \mathrm{~m}$. cada capítulo debe tener un tamaño de 3 a 6 centímetros de diámetro ecuatorial para la agroindustria.

\section{Imperial Star}

De semillas más pequeñas en comparación de las demás Variedades, el peso de cada mil semillas es de 27 gramos, es la razón por la cual se preparan almácigos para producir plántulas para su trasplante en campo definitivo.

\section{Criolla}

Esta variedad, presenta espinas en las hojas y en las brácteas, es más tolerante a plagas y enfermedades. Sus capítulos también son terminales tanto en el tallo principal como en los tallos laterales, de forma cónica, de color purpura a un inicio, según va creciendo va tornando su color a verde oscuro, con diámetro ecuatorial de hasta 17 centímetros.
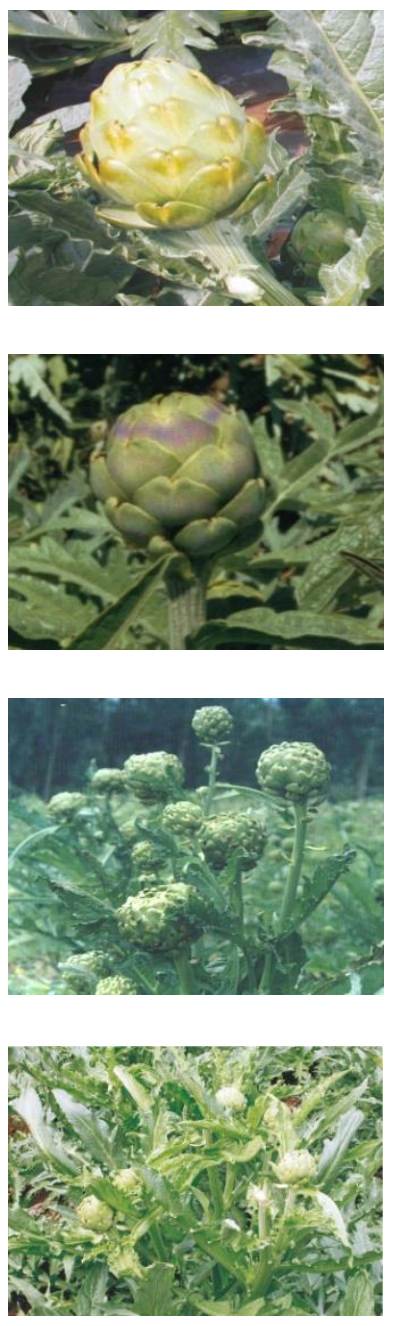

Cabe mencionar que las 5 variedades iniciales son sin espinas y está destinado para el proceso de "corazones de alcachofa" y la última variedad "Criolla" es para el proceso de "fondos de alcachofa" ambos para la agro exportación. 


\section{PROPAGACIÓN POR SEMILLA BOTÁNICA}

La alcachofa es una planta semiperenne, propagada normalmente en forma vegetativa, sin embargo, al comienzo de un cultivo, como es el caso de la introducción de variedades sin espinas en las zonas productoras de costa y sierra, una de las formas de producción y propagación es por semilla botánica.

Las principales ventajas plantados a partir de semilla botánica son:

- Esta planta semiperenne puede ser convertida en un cultivo anual e incluida dentro de la rotación de cultivos.

- Mejor sanidad del cultivo, porque la transmisión de enfermedades virales es más difícil comparado con la propagación vegetativa.

- Comparado a las plantas producidas por propagación vegetativa la siembra mecanizada es un ahorro de mano de obra y disminuye los costos de operación.

- Las plantas provenientes de semilla botánica desarrollan raíces más largas y verticales, las cuales penetran más profundamente en el suelo utilizando en forma eficiente los fertilizantes y la humedad.

De acuerdo a experiencias preliminares, se ha observado que, en costa central y valles interandinos, por las condiciones favorables de clima es posible obtener semilla botánica de alcachofa, aunque en un porcentaje inferior a lo normal.

La propagación por semilla botánica es considera tardía en comparación a otros métodos; es decir la cosecha se inicia a los 5,5 meses aproximadamente en costa y en sierra a los 6.5 meses (incluye la fase de almácigo).

\section{PROPAGACIÓN VEGETATIVA}

En la propagación vegetativa, el rendimiento óptimo y la calidad generalmente se obtiene durante los primeros años después de instalado, luego la producción tiende a declinar.

En el Perú, a nivel comercial la propagación vegetativa más generalizada es por hijuelos y esquejes. Esta forma de propagación tiene ventajas por la precocidad de las plantas y rápida producción en comparación a otros métodos de propagación, teniendo la seguridad de obtener buenas plantas capaces de producir mejor a los 4 a 5 meses aproximadamente después del trasplante, dependiendo de la zona.

Los hijuelos son brotes laterales provistos de hojas y parte de raíz que crecen del sistema rizomático de la "planta madre" que han sido cortados y luego instalados en campo definitivo.

Los esquejes son partes basales de tallos con parte de raíz y brotes, que han producido cabezuelas, han entrado en latencia y son cortados, en el período de reposo vegetativo, a unos $15 \mathrm{~cm}$. de la superficie del suelo. Para obtener esquejes es necesario esperar la finalización de la cosecha.

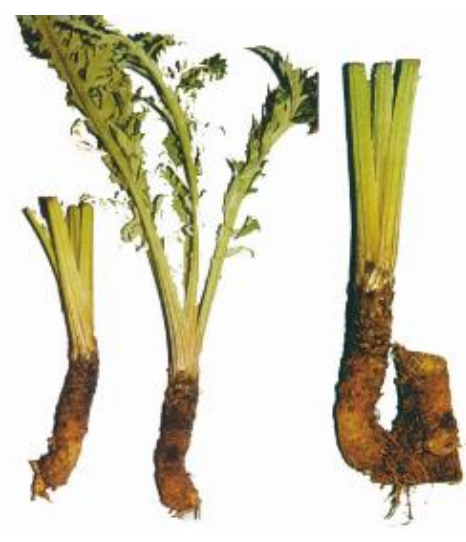




\section{PROCEDIMIENTO PARA LA EXTRACCIÓN DE HIJUELOS Y ESQUEJES}

Para hijuelos luego de seleccionada la "planta madre" y concluida la cosecha se cortan los tallos y hojas viejas para inducir la producción de hijuelos. Cuando los hijuelos tienen $4-5$ hojas (aproximadamente $20-30 \mathrm{~cm}$. de altura) son cortados y deben portar parte del tallo y raíz de la "planta madre" y así, establecerse como planta independiente para su instalación en nuevos campos. La extracción se hace de cultivos de primer y segundo año.

Para cosecha de esquejes e hijuelos, la extracción generalmente se realiza los meses de mayo, junio, julio, agosto y setiembre; cuando los hijuelos tienen $4-5$ hojas y luego plantados en campo definitivo, teniendo en consideración criterios técnicos de pureza física y varietal de categoría certificada, sanos y tratados a fin de minimizar riesgos de contaminación.

\section{FACTORES EDAFOCLIMÁTICOS QUE INFLUYEN EN LA PRODUCCIÓN DE ALCACHOFA}

El desarrollo normal de los cultivos depende de la interacción de factores externos; agua, temperatura, luz y nutrientes e internos como las hormonas o fitorreguladores.

Para el caso de alcachofa, es necesario comprender que los factores edafoclimáticos y de manejo agronómico, son determinantes en la producción del cultivo y se deben integrar en un mismo objetivo, que es de alcanzar el máximo potencial productivo del cultivo. Por otra parte, la mantención y el incremento de los volúmenes de producción, se deben principalmente a la incorporación de tecnologías y a la elección de cultivares adecuados para cada zona

En el Perú las diferencias de latitud, altitud, presencia del Océano Pacífico, la Corriente de Humboldt y la Cordillera de los Andes; constituyen los factores que ejercen mayor control sobre las condiciones climáticas del país, dando lugar a una gran variedad de climas.

La alcachofa es una planta con un vigoroso desarrollo vegetativo, un extenso sistema radicular y continua producción de cabezuelas durante tres a 5 meses aproximadamente, por lo tanto, las exigencias de agua son grandes, siendo estas exigencias variables en cantidad en las diferentes fases fenológicas del cultivo. En la costa central del Perú, se ha determinado, para el riego por gravedad, el consumo de aproximadamente $15,000 \mathrm{~m} 3 /$ ha. por lo que será necesario optar por un riego tecnificado (por goteo) a fin de subir la eficiencia de riego. Para el caso de sierra, se debe considerar que las necesidades hídricas de la alcachofa son cubiertas por las precipitaciones pluviales y el riego es considerado complementario.

El clima frío daña fácilmente las cabezuelas, a temperaturas cercanas o debajo del punto de congelación $\left(0^{\circ} \mathrm{C}\right)$, la parte más externa (brácteas) tienden a ampollarse; proporcionando primero un aspecto blanquecino en las hojas que luego se volverá de color marrón parduzco. Las lesiones superficiales causadas por el frío son estéticamente indeseables, pero no perjudican la calidad culinaria de la cabezuela.

En general la planta detiene su desarrollo cuando las temperaturas invernales son inferiores a $\operatorname{los} 5^{\circ} \mathrm{C}$ y en verano cuando alcanzan $\operatorname{los} 30^{\circ} \mathrm{C}$. La temperatura optima puede 
situarse alrededor de los $24^{\circ} \mathrm{C}$. Acepta límites térmicos de $7^{\circ} \mathrm{C}$ en invierno y $29^{\circ} \mathrm{C}$ en verano, pero encuentra su mejor hábitat cuando la temperatura media se mantiene constante alrededor de los $13^{\circ} \mathrm{C}$ durante la estación fría y $22^{\circ} \mathrm{C}$ en la cálida.

Para la apertura de los botones florales requiere acumular cierta cantidad de frío, proceso que se denomina vernalización. Cuanto mayor sea el frío acumulado en el invierno, mayor será el vigor de las plantas para la apertura del botón floral y la producción de cabezuelas compactas y de calidad.

La vernalización se da en las zonas andinas, pero no en condiciones de costa con suave clima marítimo de los valles costeros, en los que la inducción floral y producción se dilata más que en la sierra por las condiciones antes indicadas. No obstante, a ello la apertura del botón floral puede ser estimulada notablemente mediante la acción del Ácido Giberèlico, por lo que la falta de frío no sería una limitación.

En la zona del valle del Mantaro, donde la baja temperatura favorece el desarrollo de las cabezuelas, las variedades sin espinas producen cabezuelas de gran tamaño, pero se ha observado que un cierto $\%$ de las cabezuelas no cierran bien debido a su forma achatada, dejando una abertura al centro "ombligo" expuesta a la lluvia y a la "pudrición".

La humedad relativa tiene gran importancia en el manejo del cultivo de alcachofa, principalmente en la formación de cabezuelas, cosecha y conservación del producto cosechado; siendo necesario tener una humedad alta en el ambiente para evitar pérdidas de agua en las cabezuelas.

La radiación solar incide claramente en la fotosíntesis y a través de esta en el crecimiento vegetativo en la inducción floral y en el tamaño, color y composición de las cabezuelas. Todo ello determina la cantidad y calidad de la producción.

La bibliografía indica que la alcachofa a nivel mundial difícilmente es sembrada a altitudes que pasan los $2000 \mathrm{msnm}$. En la costa peruana, se ha observado plantaciones cercanas a las playas (Guadalupito, La Libertad). Sin embargo, en sierra las altitudes máximas, que han sido evaluadas corresponden a altitudes cercanas a $3400 \mathrm{msnm}$. La mejor altitud es el Valle del Mantaro (3 $300 \mathrm{msnm}$ ).

Para la instalación de cultivos en nuevas zonas es necesario realizar un análisis previo, principalmente de las condiciones edafoclimáticas y sus respectivas interacciones. La altitud únicamente no es el parámetro que determina la instalación en nuevas zonas.

\section{VALOR NUTRITIVO Y MEDICINAL}

Para tenerlo en cuenta, de acuerdo a su composición la alcachofa no es solo una hortaliza nutritiva sino altamente protectora de la salud, además de adecuada para regímenes de conservación de la figura. Por su contenido de fibra, vitamina C y flavonoides antioxidantes previene la formación de tumores, cáncer de colon, senos y próstata, además de problemas cardiovasculares. Su alta proporción de magnesio le confiere efectos antidepresivos y refuerza el sistema reproductivo, sumado al folato reduce en las mujeres el riesgo de ciertos defectos cerebrales o espinales del feto durante la gestación. La alcachofa contiene un alcaloide llamado cinarina que es estimulante del hígado y reduce los cálculos biliares, así como el colesterol y la formación de ácido úrico. 
Por contener también insulina, es conveniente que forme parte de la dieta de los diabéticos. Todas estas propiedades únicas en una hortaliza debieran ser mencionadas en cualquier programa dirigido a la promoción de su consumo.

Aunque la parte que forma la cabeza, tan apetitosa y comestible, tiene muchas sustancias nutritivas, es en las hojas de la planta donde residen la mayoría de sus propiedades terapéuticas y protectoras. El consumo de alcachofa ayuda a reducir la cantidad de colesterol en la sangre y a contrarrestar el estreñimiento. Al ser diurética y depurativa, tiene efectos muy positivos en casos de retención de líquidos; además, los preparados a base de hojas de alcachofa favorecen la digestión de las grasas y estimulan la secreción de la bilis, especialmente en los casos de digestiones pesadas y lentas, convirtiendo a esta planta en el aliado más natural de una buena digestión.

Tiene propiedades para la diabetes, dado que es hipoglucémica (disminuye el azúcar en la orina). Asimismo, contribuye a regular las funciones hepáticas y renales.

\section{Tabla 2}

\section{Calendario de producción de alcachofa por departamentos en Perú}

\begin{tabular}{|c|c|c|c|c|c|c|c|c|c|c|c|c|}
\hline Dpto. & Ene. & Feb. & Mar. & Abr. & May. & Jun. & Jul. & Ago. & Sep. & Oct. & Nov. & Dic. \\
\hline \multicolumn{13}{|l|}{ La Libertad } \\
\hline \multicolumn{13}{|l|}{ Ancash } \\
\hline \multicolumn{13}{|l|}{ Lima } \\
\hline \multicolumn{13}{|l|}{ Ica } \\
\hline \multicolumn{13}{|l|}{ Junín } \\
\hline \multicolumn{13}{|l|}{ Apurímac } \\
\hline \multicolumn{13}{|l|}{ Andahuaylas } \\
\hline Huancavelica & & & & & & & & & & & & \\
\hline
\end{tabular}

Fuente: Elaboración: Propia

\section{SELECCIÓN, PROPAGACIÓN Y RENDIMIENTO}

La alcachofa es una planta de flores alógamas, que requieren polinización cruzada porque sus estambres y pistilo no maduran al mismo tiempo. Esto da lugar a que al multiplicarse por semilla segregue notablemente dando origen a plantas de talla y follaje variado, con capítulos de diferente forma, tamaño y color a las de la planta madre. Es también una especie poco mejorada, por lo que tiene un inmenso potencial genético para el desarrollo de nuevos ecotipos.

El INIA trabajó en investigación con la selección de variedades como la Criolla, Lorca, Green globe, INIA1 y INIA2 supuestamente con mejor rendimiento que otras variedades implementadas en el valle del Mantaro, con uso de semillas vegetativas, es decir a través de hijuelos y esquejes, en convenio con la Universidad UDEA. De cuyos resultados se obtuvo que la variedad criolla con espinas supera en rendimiento con $7894 \mathrm{~kg} / \mathrm{ha}(5263 \mathrm{doc}$.), y la Green globe con $3762 \mathrm{~kg} / \mathrm{ha}$. Seguido por la variedad INIA2 con rendimiento promedio de $2757.2 \mathrm{~kg} / \mathrm{ha}$. 


\section{LABORES CULTURALES}

\section{Preparación del terreno}

Se realiza con mucho cuidado por tratarse de un cultivo que en el caso de las variedades de alcachofa son semiperennes y que puede durar varios años. Como la raíz es profunda se requiere subsolado en caso de suelos pesados y compactados para facilitar su penetración y drenaje del agua excedente, nivelación del terreno para el riego a fin de evitar anegamientos y susceptibilidad de las plantas, sobre todo en su primera etapa de desarrollo, La adición de materia orgánica al suelo al momento de su preparación es muy importante con una dosis de 5 a $10 \mathrm{TM} /$ ha., por lo que la materia orgánica, es poco eficiente como fertilizante nitrogenado; aunque sea excelente como aportante de coloides para fijar cationes, ácidos húmicos, sustento de flora microbiana, retención de humedad y amortiguadora de la alcalinidad y salinidad, en otras zonas del mundo se recomiendan aplicar de 30 a 40 TM/ha. de materia orgánica (España, Italia, Francia, EEUU, etc.)

\section{Plantación en campo definitivo}

La plantación se realiza con hijuelos provenientes de campos certificados (INIA), la misma se procede a preparar el "hijuelo" cortando las hojas por la mitad, con la finalidad de reducir la transpiración y deshidratación mientras se desarrollan las raíces absorbentes, se hace colocando el hijuelo a $15 \mathrm{~cm}$. de profundidad en la parte de las "costillas" del surco previamente preparado haciendo un pequeño "hoyo" con un madero de punta y regándolo inmediatamente, es importante mencionar que el riego debe realizarse cada 3 a 4 días después del trasplante a fin de asegurar el buen prendimiento de las plántulas, la densidad de la plantación debe ser de $1.00 \mathrm{~m}$ x 0. 80m.logrando una población de 12,500 plantas por hectárea.

\section{Fertilización}

La formulación recomendada es de 300-180-350NPK, Ca-150, S-80 y Mg- 40. Como fuente de fertilización puede ser la Urea, F.D.A. Cloruro de potasio y Sulfomag, complementándose con abonos foliares en base a calcio, Mg. y boro.

1. El Nitrógeno se fracciona en tres aplicaciones, la primera a los 45 días d.d.s. la segunda a los 95 d.d.s., con la mitad del calcio, la tercera y última a los 135 d.d.s., con la otra mitad del calcio.

2. El fósforo, P2O5, se utiliza el 50\% a los 45 d.d.s. junto con el S. y Mg. y el resto a los 95 días d.d.s. con el resto de $\mathrm{S}$. y el $\mathrm{Mg}$.

3. E1 K20 se fracciona en dos partes, a los 45 d.d.s. el $50 \%$ y el resto a los 95 d.d.s.

\section{Riego}

La alcachofa es una planta de gran expansión foliar y turgencia, por lo que necesita más que otras especies y que se mantenga permanentemente en "capacidad de campo" sobre todo durante la etapa de formación de capítulos. Según experiencias realizadas por el INIA - Huancayo, para cultivo se utiliza $8,000 \mathrm{~m} 3 /$ ha. Por riego por superficie, y riego por goteo, el consumo de agua puede reducirse hasta 5,000 m3/Ha si se programa bien. La adopción de un riego tecnificado en el futuro debe darse para una agricultura exigente como la de exportación. 


\section{Control de malezas}

En la alcachofa el mejor modo de controlar las malezas es antes de la preparación de terreno para el trasplante, realizar un riego pesado antes de 30 a 40 días del trasplante a fin de facilitar la germinación de las malezas que quedaron en la campaña anterior o que fueron traídas por el viento, una vez germinado las malezas se hace araduras profundas y se voltea las plantas brotadas, después de ello se inicia la preparación del terreno.

También podrían utilizarse herbicidas pre emergentes que no afecten a las plántulas de alcachofa y menos a los hijuelos, previa recomendación técnica.

\section{Aporque y podas}

El aporque es para dar un mejor soporte a las plantas y favorece la formación de hijuelos, es una operación propia de los campos regados por gravedad y es aconsejable hacerlo alrededor de los 45 a 60 días, las podas se realizan hasta en dos ocasiones, eliminando las hojas basales cercanas al suelo y viejas además portadoras de la "ramularia" que de no hacerlo afectaría al cultivo también por la presencia de "babosas"; así como para facilitar el acceso de los cosechadores.

\section{Poda de formación}

Una vez concluida la cosecha o recolección del primer ciclo de cultivo (primer tallo en producción), y cada ciclo siguiente, se corta el tallo principal de la planta al ras del suelo. Esta poda favorece el nuevo crecimiento de la planta y formación de frutos nuevos (caso de valles interandinos en que la cosecha es continua y que por efecto de las heladas en otras zonas de sierra ya no producen), así como el desarrollo de hijuelos. Este corte se realiza a bisel (angulado) con una podadora.

\section{Control de plagas y enfermedades.}

Aunque no tiene muchos enemigos la alcachofa porque no son precisamente apetecibles a las diversas especies de insectos que constituyen las plagas hortícolas; tenemos algunas de significancia que atacan en determinadas circunstancias y puede provocar daños importantes tanto en su parte aérea como desde el suelo, el control fitosanitario puede ser preferiblemente preventivos con la práctica de las buenas prácticas agrícolas y finalmente con plaguicidas recomendados por la empresa exportadora

\section{Cosecha}

La cosecha suele iniciarse aproximadamente a los cuatro meses del trasplante de los hijuelos y hasta un mes más cuando se emplea plántulas (zona de costa) y en las zonas de Sierra se inicia a los 5 a 6 meses. Para las cosechas siguientes, cuando hay desbrozo (para segunda campaña), el inicio de la cosecha se produce a partir de los cuatro meses del brote.

El período de cosecha, puede variar en la costa entre 90 y 120 días y en la sierra entre 120 hasta 180 días. Cuando el destino es el mercado nacional (con espinas) la cosecha se realiza cada 15 días y cuando es para agroindustria se hace cada 7 días, para evitar que los cardos se pasen de tamaño.

La cosecha manual se hace con un cuchillo en forma curvo bien afilado, dejando hasta $10 \mathrm{~cm}$ del tallo floral que sirve como reserva de agua para retardar la deshidratación (con espinas), para lo de sin espinas se deja solo de 2 a $3 \mathrm{~cm}$. de tallo floral, porque de 
inmediato entran al procesamiento y el pesaje incluye dicho tallo, la cosecha para la agro exportación con diámetro ecuatorial menor a $7.0 \mathrm{~cm}$. de calibre en las variedades sin espinas y menores de $11.00 \mathrm{~cm}$. de calibre en la variedad con espina criolla

\section{Desbroce o chapodo}

Se realiza al finalizar la cosecha y para dar inicio a una nueva campaña, se corta cuando el 95\% de las plantas ha llegado al final de su período vegetativo, en los campos quebrados de la sierra la operación se hace con herramientas manuales, pero en la costa, donde las extensiones son más grandes y los terrenos son planos, la operación se hacen con desbrozadora o una trituradora de follaje como las usadas en el espárrago; pasándola a ras del suelo o en dos pases si el follaje es tan grande que atora la máquina. se recomienda cortar el tronco entre 5 y $10 \mathrm{~cm}$ sobre el nivel del suelo para favorecer el brotamiento de nuevos hijuelos.

El Desbrozado o chapodo estimula la emisión de brotes laterales en la corona de la raíz, que luego se cortan con lampa afilada o pico en un $50 \%$ de la corona con parte de la raíz madre para nuevas plantaciones (esquejes o hijuelos) dejándose el que esté más alineado con la hilera para la renovación de la planta.

\section{CONCLUSIONES}

La principal conclusión de esta revisión es que, de acuerdo al esfuerzo, la competencia y el interés de los agricultores, las probabilidades de obtener un buen rendimiento de cultivos de exportación como la alcachofa en zonas interandinas de nuestro País es posible desarrollando como cultivo alternativo rentable y saludable. A diferencia de otros cultivos que fracasaron como cultivos promisorios sin apoyo técnico ni destino de mercado por parte del estado, se menciona algunas conclusiones finales:

- Las zonas interandinas de nuestro país ofrecen buenas posibilidades de desarrollar cultivos alternativos como la alcachofa destinados al mercado nacional e internacional

- Los trabajos de investigación cuyos resultados positivos sirven para que el productor agrícola tenga la oportunidad de mejorar sus ingresos incursionando en un mercado competitivo y de exportación con un cultivo alternativo como es la alcachofa y consecuentemente mejorar su calidad de vida, la investigación es importante en estas zonas la que debería plantearse y ejecutarse por las entidades de investigación correspondiente incluido las universidades que juegan un papel importante en el desarrollo económico social de nuestro País, la que debe hacerse en forma integral y suma de esfuerzos.

- El papel del Estado es fundamental en la transferencia de conocimiento y apoyo con la asistencia técnica y capacitación, asegurando la producción y el mercado, con metodologías adecuadas como las "Escuelas de campo" y el principio de "aprender haciendo" que fortalecerán las capacidades de nuestros agricultores de estas zonas.

- Se deben desarrollar tecnologías de producción, cosecha y post cosecha sostenibles y competitivas con aplicación de las buenas prácticas agrícolas BPA, para el cultivo de la alcachofa. 
- Se deben identificar nuevas variedades de alcachofa con alto potencial productivo y calidad comercial orientada a mercados competitivos de agro exportación según su comportamiento frente a los factores edafoclimáticos de las zonas interandinas y considerar en los "planes de cultivo y riego" nacionales.

- Asegurar la provisión del recurso hídrico e implementar el sistema de riego tecnificado en la zona andina del Perú por parte del Estado peruano en convenio con fuentes extranjeras

\section{REFERENCIAS BIBLIOGRÁFICAS}

Aduanas del Perú (2004) Boletines estadísticos [en línea] [Referencia 24 julio 2004] http: aduanet.gob.pe

BizzuBikoff, P.Y.; Gonzales, G-F.; Hans, B.R.; Ismiño, A.J. y Mesones, M.J. (2005) Plan estratégico para la cadena productiva de la alcachofa en Junín, Trabajo de tesis para obtener el grado de Magister en administración de empresas en el CENTRUM de la Pontifica universidad católica del Perú. 245 pág.

Calderón M. C. (2005) “Cosecha y post cosecha de la alcachofa, Procesadora SAC.

DRA - JUNIN (1997) Programa de producción del cultivo de alcachofa, campaña 1997-1998, Sub Región Junín, Región Andrés Avelino Cáceres, Huancayo

INFOAGRO (2012) El cultivo de la alcachofa (en línea) 2012, http://infoagro.com/hortalizas/alcachofas.

Marín de Burgos, E. (2008) "Curso virtual de cultivo y comercialización de la alcachofa" Iberagro Lima SAC.

Minag (2004) bttp. Frente web.minag.gob.pe [sisalgricola.gob.pe]

Ministerio de Agricultura (2001) Cultivo de alcachofa sin espinas" Instituto nacional de investigación agraria INIA,

Norma Técnica Peruana NTP 011.125:2006 Buenas prácticas agrícolas para el sector hortofrutícola.

Quispe R. J. (2006) "Manual del cultivo de alcachofa" uso y manejo, financiado por la USAID. y el Fondo Ítalo Peruano.

Robles, F. (2000) La alcachofa, nueva alternativa para la agricultura peruana, PROMPEX, Lima. 